In No. 2 of the glass copies from the Ottumwa photographs, x 869 , the moon is also apparently quite circular ; but in No. 4, where the bright depths of the chromosphere are just appearing, the polar diameter is distinctly the Iongest. I have been led to conclude that the ellipticity is cansed by an unequal eating over or irradiation at the polar and equatorial portions of the limb, and that in this lies proof that at the sun's equatorial regions the brighter layers of the chromosphere extend to a greater height than near the poles. We know from other sources that the corona generally, and probably also its lower portions, were not so bright in 1870 as in 1869 and 1871 ; hence the eating over between the prominences has been comparatively slight, and no detectable difference has been caused between the polar and equatorial diameters.

\section{The British Museum}

IT is strange that such a statement as that advanced by Mr. W. Stanley Jevons in NATURE, Nov. 13 , has so long remained unchallenged, viz. "that the British Museum exists not so much for the momentary amusement of gaping crowds of country people, who do not understand a single object on which they gaze, as for the promotion of scientific discovery, and the advancement of literary and historical inquiry." "No one will dispute the truth of these statements, but substitute the word "instruction" for "momentary amusement," and I very much cloubt if his views would meet with public approval. I have always looked upon the British Museum as the National Museum, and preeminently' the Museum of the people, and, as such, the arrangement and labelling of the specimens should be of the most simple and instructive nature : nor is such an object opposed to, but perfectly coincident with, the highest interests of science. No wonder the Museum is filled with "gaping crowds" when nothing is done to instruct them as to the nature of objects of which Mr. Stanley Jevons himself admits they are ignorant, nor to provide them with a suitable and educational guide-book, without which they are as sheep without a shepherd When the Trustees of this Museum can spare time, they may, perhaps, be able to direct attention to the fuller development of its scientific and educational functions ; as regards the former, by the establishment of one exclusively British Department; and, as regards the latter, by carrying out the very obvious suggestions which I have advanced. The view that science, or rather scientific men, should have a monopoly of the benefits to be derived from this Institution is astoundingly selfish and narrowminded. If such are the views of the Trustees, the British Museum had better be closed to the public.

S. G. P.

\section{Moraines}

HAVE recently been visiting some of those spots which, according to Prof. Ramsay and other geologists, are marked by morain es of the ancieint glaciers of North Wales, and several of which are supposed to form the retaining walls of lakes or tarns: and a question has arisen in my mind to which neither my own consideration nor any of the few books here at my command has afforded any answer.

A glacier which has retreated from its terminal moraine, is always the source of a stream of water, and this stream always cuts through the terminal moraine, and makes in it a gap often wide, and always reaching down to the level of the original soil. A terminal moraine from which a glacier has retreated is the rim of a saucer with a cleft in it, extending to the bottom of the saucer. It consequently cannot and does not act as a retaining wall, and the water from the glacier does not form a lake, but flows out as a stream. No better illustration of this fact occurs to me than the Rhone glacier, with its long series of terminal moraines, all intersected and cut through to the ground by the infant Rhone. How then can a terminal moraine ever form a lake? But if a terminal moraine alone cannot form a lake, a terminal moraine with a stopper put into its hole might. But how is the stopper to get there? Why should débris or stones or any other stopper stay in the one place in the whole line where there is no resistance?

Where the basin of the lake is supposed to be constituted by rock basin and a moraine on its rim, what $I$ have said has, of course, no application to the rock basin, but seems to me to apply to show that the moraine cannot constitute any part of the retaining barrier.

And again, where the retaining barrier is supposed to be constituted by a marine terminal moraine, i.e. by a moraine deposited under the sea, the observations I have made seem not to apply.
My questions apply to ordinary terrestrial terminal moraines, They are so simple and go so to the root of the whole notion that such moraines can form lakes that I presume they have been answered long ago by geologists. Can any of your readers tell me where such answers are given or wha: they ought to be?

Bryn Gwyn, Penmaenmawr, Oct. I3

EDW. FRY

The Elevation of Miountains and the Internal Condition of the Earth

I HAVE just read in NATURe, vol, ix. p. 62, Captain Hutton's letter to the Rev. Osmond Fisher on the "Elevation of Mountains and Volcauic Theories." I was also indebted some time since to the courtesy of Captain Hutton for a copy of his lecture on the Formation of Mountains, delivered at Wellington, New Zealand, November, 1872 . Without entering at present into a discussion upon the particular theory which finds favour with him, I may be permitted to call attention to the fact that Sir William Thomson's views as to the rigidity of the earth have been distinctly called in question in a former number of this journal, which has probably not reached Captain Hutton. I reier to my communication entitled "The Rigidity of the Earth," printed in NATURE, vol. vii. p. 288. Captain Hutton expresses his belief that the theory of internal rigidity has probably a weak point somewhere. I venture to think that its weak points are so many as to make it a theory too brittle to form a support to any geological superstructure.

Dublin, November 28 .

H. HENNESSY

\section{METEOROLOGIC SECTIONS OF THE} ATMOSPHERE

${ }^{\prime} \mathrm{HE}$ primary object of meteorology is to record the pressure, the temperature, the moisture, the electricity, and the movements of the atmosphere. It is desirable, however, that observations on these subjects should be combined with the elements of time and distance. At the general meeting of the Scottish Meteorolog:cal Society on June 26,1867 , I proposed the method, since generally adopted, of reducing the intensity of storms to a rumerical value by the calculation of barometric-gradients, or in other words by dividing the difference of reading of any two barometers by the distances between the stations where such barometers are placed, thus introducing a nomenclature of universal application, by which the movements of any aerrial current, and particularly the wind force of storms, may in every part of the world be reduced to one standard of comparison; and the calculation of thermometric, nygrometric, and electric gradients was subsequently proposed. Since then I suggested to the same society the extension of this system by the establishment of a series of barometers placed at short distances from each other in one or more than one direction in azimuth, so as to give horizontal atmospheric sections for pressure. By means of such lines of section the maximum gradient during storms might, from the nearness of the stations to each other, be ascertained, and thus the phenomena of local storms and other local atmospheric disturbances investigated with some hope of success; and since then a horizontal section extending landwards from the sea-shore has been proposed for temperature and moisture, chiefly with the view of determining the extension inland of the influence of the sea on climate.

It would be important were the system of meteorological sections $\epsilon$ xtended to the vertical as $w=l l$ as the horizontal plane. If a string of stations were placed at short horizontal distances from each other and extending from the bottom to the top of a high hill or mountain, the section thus obtained would show the relative distribution at different times, of pressure, temperature, humidity, $\& c$. , in the vertical plane. In Scotland, the existing station of Drumlanrig is I9 I feet, and that at Wanlockhead 1,334 feet above the sea, so that the difference in elevation is I, I43 feet. The horizontal distance between them is 9 miles, and in all probability the necessary number of intermediate stations could be established. In Hong Kong the town of Victoria is 1,666 feet below that of Blockhouse Victoria Peak, while in Switzerland 
and other mountainous districts many other suitable places might no doubt be found.

Would it not be possible to secure funds for establishing at least one such atmospheric section on the slope of some steep hill or mountain in connection with a station or two on an adjoining level district of country?

\section{THOMAS STEVENSCN}

\section{ON THE HYSIOLOGICAL ACTION OF} $O Z O N E$

$A T$ a meeting of the Royal Society of Edinburgh on the Ist inst., a communication was read from $\mathrm{Mr}$. Dewar and Dr. M'Kendrick on the physiological action of ozone. The authors, in the first place, pointed out that little was known regarding the action of this substance, except its peculiar smell and the irritating effect it had on the mucous membrane of the respiratory tract. Schönbein had shown that a mouse died in five minutes in an atmosphere highly charged with ozone; and it was this distinguished investigator who asserted that there was a relation between the quantity of ozone in the air and the prevalence of epidemic diseases. The action of ozone was therefore a subject to be elucidated; and having occasion to employ ozone in another experimental inquiry, the authors resolved to investigate the matter. The ozone was made by passing a current of dry air or oxygen from a gasometer through a narrow glass tube, bent for convenience like the letter $U$, about $3 \mathrm{ft}$. in length, and containing a platinum wire $2 \mathrm{ft}$. in length, which had been inserted into the interior of the tube, and one end of which communicated with the outside through the wall of the tube. Round the whole external surface of this $U$-shaped tube, a spiral of copper wire was coiled, and the induction current from a coil giving half-inch sparks was passed between the external copper to the internal platinum wire, so as to have the platinum wire as the negative pole in the interior of the tube. After the stream of gas was ozonised by the transmission of the induction current, it was washed by passing through a bulb-tube containing caustic potash, when air was employed, or water when pure oxygen was used, in order to eliminate any traces of nitrous and nitric acids that might have been formed. By means of the gasometer, the volume of gas passing through the tube could be ascertained.

The action of ozone was determined $\langle\mathbf{I}\rangle$ on the living animal enclosed in an atmosphere of ozonised air or of ozonised oxygen; and (2) on many of the individual living tissues of the body. Numerous experiments were made on frogs, birds, mice, white rats, rabbits, and on the authors themselves. Two experiments may be given here as illustrating the action of ozone on (I) a cold, and on (2) a warm-blooded animal.

I. On a Frog.-A large, bealthy male frog was introduced into the air chamber, through which a current of air was passing sufficient to fill a litre jar in three minutes. At the end of two minutes, the respirations were ninetysix per minute. The induction machine was then set to work so as to ozonise the air. In half a minute, the eyebalis were retracted, so as to appear deeply sunk in the orbits, and the eyelids were closed; the respirations were now eight per minute. At the end of six minutes, the animal was motionless, and there were no respiratory movements. Pure air was then introduced. In half a minute, there was a slight respiratory movement, and in eight minutes there were eighty.five respirations per minute. At the end of other twelve minutes, ozone was again turned on, with the same result. A frog will survive in a dormant condition in an atmosphere of ozonised air for several hours. In one case, the animal died. The heart was found still pulsating. It was full of dark blood. The lungs were slightly congested. The blood was venous throughout the whole body. In ozonised oxygen the effects were, on the whole, the same as in ozonised air, with this difference, that in ozonised oxygen the respiratory movements were not affected so quickly, and were never completely arrested.

2. On a bite Mouse.-A full grown and apparently healthy white mouse was introduced into a vessel through which a stream of air was passing at the rate of eight cubic inches per minute. Five minutes thereafter, the animal was evidently at ease, and the respirations were over 100 per minute. The air was then ozonised. One minute after, the respirations were slower, but the number could not be ascertained owing to the animal moving uneasily about. In four minutes from the time of the introduction of the ozone, the respirations were thirty-two in a minute. The mouse now rested quietly, occasionally yawned, and, when touched by a wire, moved,- -but always so as to remove its nose from the stream of ozonised air. At the end of fifteen minutes, the animal had slight convulsive attacks, which increased in severity until it died-nineteen minutes after the introduction of the ozone. The post-mortem appearances were great venous congestion in all parts of the body. The heart pulsated for several minutes after systemic death. In ozonised oxygen, death was delayed for a much longer period. Instead of dying at the end of fifteen or twenty minutes, as happened to mice in ozonised air, they lived for forty or sixty minutes. It is noteworthy that even after death in ozonised oxygen; the blood was found to be in a venous condition.

On breathing an atmosphere of ozonised air themselves, the authors experienced the following effects:-a suffocating feeling in the chest; a tendency to breathe slowly ; irritation of the fauces and glottis; a tingling of the skin of the face and conjunctivæ. The pulse became feebler. The inhalation was continued for eight minutes, when they were obliged to desist; and the experiment was followed by violent irritating cough and sneezing, and for five or six hours thereafter by a sensation of rawness in the throat and air-passages.

The general result of the inquiry may be briefly stated as follows :-

I. The inhalation of an atmosphere highly charged with ozone diminishes the number of respirations per minute.

2. The cardiac pulsations are reduced in strength and this organ is found beating feebly after systemic death.

3. The blood is found after death to be in a venous condition, both in those cases of death in an atmosphere of ozonised air and of ozonised oxygen.

4. The inhalation of an ozonised atmosphere is followed by a lowering of the temperature of the body to the extent of at least $3^{\circ}$ to $5^{\circ}$. C.

5. The inhalation of ozone does not exercise any appre ciable action on the capillary circulation, as seen in the web of the frog's foot under the microscope (200 diameters).

6 . In the bodies of frogs killed in an ozonised atmosphere, the reflex activity of the spinal cord is not appreciably affected.

7. By means of a myographion, the work done (in gramme-millimetres) by the gastronemius muscles of frogs subject to the action of ozone was noted. The muscles were stimulated by a single opening or closing induction shock produced by Du-Bois-Reymond's apparatus and a Daniell's cell. The result was that the contractility and work-power of the muscle were found to be unaffected.

8. Ozone has an action on the coloured and colourless corpuscles of human blood and of frog's blood resembling that produced by a weak acid; and in the case of the coloured corpuscles of the frog like that of a stream of carbonic acid. The corpuscles of animals killed in an ozonised atmosphere are normal in appearance.

9. Ciliary action is not affected by a stream of ozonised air or oxygen, provided there is a considerable amount of 